\title{
Trabajo Social y teatro: considerando las intersecciones
}

\author{
Social Work and theatre: considering intersections
}

\author{
Manuel F. VIEITES \\ Escuela Superior de Arte Dramático de Galicia \\ Universidad de Vigo, España \\ mvieites@uvigo.es
}

Recibido: $28 / 05 / 2015$

Revisado: 08/06/2015

Aceptado: 25/11/2015

Disponible on line: 20/01/2016

\section{Resumen}

El teatro es una forma cultural y artística que implica un proceso de comunicación entre creadores y receptores en un espacio y en un tiempo que se sitúan en la esfera pública, lo que ha permitido que a lo largo de los siglos haya servido como espacio de expresión, intercambio o debate de todo tipo de ideas, causas y luchas. En ese proceso están implícitos procesos de expresión, creación y recepción por medio de los cuales las personas muestran, analizan y cuestionan formas de ver y entender la vida, maneras de ser y de estar en el mundo; de ahí deriva su potencial educativo, cultural, social y político, avalado por numerosos estudios e investigaciones. En este trabajo, que tiene una orientación teórica asentada en una revisión de literatura pertinente, consideramos diferentes intersecciones que se producen entre teatro y Trabajo Social, para señalar también que la expresión dramática y la expresión teatral ofrecen metodologías substantivas en la consecución de algunos objetivos del trabajo social, especialmente en ámbitos como la alfabetización crítica, la reflexividad y el reconocimiento, la concientización, la participación social, el desarrollo personal y/o comunitario, la apropiación de capital cultural o el acceso al bienestar personal y social.

Palabras clave: teatro, Trabajo Social, alfabetización, concientización, participación.

\begin{abstract}
Theatre is a cultural and artistic form that involves a process of communication between creators and is received in a space and time located in the public sphere, which has meant that, over the centuries, it has acted as a space for expression, exchange and debate regarding all manner of ideas, causes and struggles. Implicit within this process are processes of expression, creation and reception, by way of which people demonstrate, analyse and question ways of seeing and understanding life, and ways of being and existing in the world. This gives rise to educational, cultural, social and political potential, which has been endorsed in numerous studies and investigations. In this work, in which theoretical orientation is established through a review of the relevant literature, we consider different intersections that occur between theatre and social work in order to also show that dramatic and theatrical expression offers substantive methodologies for achieving some objectives of social work, particularly in areas such as critical literacy, reflexivity and recognition, awareness raising, social participation, personal and/or community development, ownership of cultural capital and access to personal and social wellbeing.
\end{abstract}

Keywords: theatre, Social Work, literacy, awareness raising, participation.

Referencia normalizada: Vieites, M. F. (2016): «Trabajo Social y teatro: considerando las intersecciones». Cuadernos de Trabajo Social, 29(1): 21-31.

Sumario: Introducción. 1. El teatro en su naturaleza. 2. Intersecciones: la construcción del sujeto receptor. 3. Intersecciones: la construcción del sujeto creador. 4. Conclusiones. 5. Referencias bibliográficas.

\section{Introducción}

En su trayectoria profesional muchos especialistas en Trabajo Social se habrán de encontrar con la práctica teatral por todo lo que ésta, en su dimensión educativa y sociocultural, puede aportar a todas aquellas personas con las que trabajan a diario (Onieva, 2011). Al considerar la trayectoria de una pionera, como Jane Addams (Vázquez Aguado, 2006), comprobamos que la práctica teatral tenía en Hull House especial relevancia. Decía Addams (1911):

I have come to believe, however, that the stage may do more than teach, that much of our cu- 
rrent moral instruction will not endure the test of being cast into a lifelike mold, and when presented in dramatic form will reveal itself as platitudinous and effete ${ }^{1}$.

Para destacar, luego, que el teatro era un «reconstructing and reorganizing agent of accepted moral truths» $\rangle^{2}$ (p. 391). En Hull House el teatro se concebía en su doble vertiente de espacio para la creación y espacio para la difusión, como lo hará poco después, en 1917, Percy MacKaye (2015) al señalar que «en el arte del teatro nuestros trabajadores sociales debieran buscar lo que precisan», «un método especializado y científico de cooperación social» (p. 458).

Diremos de partida que, si bien la bibliografía que se ocupa de la dimensión educativa o sociocultural del teatro es extensa, la disponible en el caso que nos ocupa es escasa y las consultas en bases de datos como Teseo, Dialnet o RedalyC no ofrecen resultados esperanzadores, aunque aumenten en Scopus, y en Proquest se encuentren algunos trabajos de interés, aunque sean de carácter genérico. Tales aportaciones ofrecen resultados de la aplicación de algunas prácticas artísticas, pero no ofrecen una visión general de las intersecciones entre teatro y Trabajo Social, y sin mostrar aportes para la comprensión de lo que el teatro implica como actividad. En esa dirección, este trabajo busca ofrecer una síntesis de los fundamentos teóricos que sustentan las intersecciones entre teatro y Trabajo Social y una panorámica de sus posibilidades en diferentes ámbitos de actuación. También persigue mostrar que el teatro, en tanto praxis que implica una participación activa del sujeto y de la comunidad, sea como agente creador o como receptor, es una poderosa herramienta para promover procesos de empoderamiento y emancipación, a través de la recuperación de la palabra y de la capacidad de elaborar, presentar y compartir discursos alternativos en la esfera pública.

\section{El teatro en su naturaleza}

En una glosa a «El nacimiento de la tragedia» de Nietzsche, Dieste (1995) mostraba su visión del nacimiento del teatro como manifestación cultural, cuando escribía que,

En alguna vendimia se cuentan episodios felices de los ausentes y los muertos. El que los cuenta va y viene y se agita y representa. Y hay un instante de júbilo y de embriaguez en que todos se reconocen con sorpresa, porque se recuerdan. Entonces narran unos el mito de los otros, y se representan (p. 211).

Es difícil expresar con tanta sencillez la complejidad que encierra el teatro y su naturaleza, que parte de la capacidad y la necesidad del ser humano de ser otro, de elaborar las más diversas narrativas, y de construir y reconstruir las historias. El teatro es también un acto de comunicación entre dos personas en la que una asume el rol de actor y la otra el de espectador, y en el que se dan procesos de expresión, creación y recepción, lo cual implica que tanto una como la otra posean el capital social, cultural y teatral necesarios para el desempeño de tales roles; un capital que se puede adquirir en la propia comunidad a través de la tradición, como ocurre con el teatro popular, o mediante procesos diversos de formación y/o de participación en la esfera sociocultural pública. En consecuencia, al hablar de teatro hemos de considerar áreas de trabajo, como la formación, la expresión, la creación y la recepción, resultando tan relevante la formación para la expresión y la creación, como la formación para la recepción.

Para tomar conciencia de lo que el teatro puede aportar al Trabajo Social, consideremos que aquél:

a) Es una actividad que se presenta en la esfera pública. Implica el hecho de mirar y ser mirado, de escuchar y ser escuchado, siendo ocasión para tomar la palabra y expresar (o conocer) una determinada posición, individual y colectiva, una forma de ver el mundo, una ideología en tanto idea del ser humano, de sus valores y creencias. Supone encuentro, comunicación y diálogo entre personas.

b) Es una actividad colectiva que implica una dinámica grupal con procesos de debate, delibe-

${ }^{1}$ «He acabado por creer, sin embargo, que la escena puede hacer algo más que enseñar, que una buena parte de nuestra instrucción moral actual no pasaría la prueba si fuera trasladada a un molde natural y que, al presentarse en forma dramática, se mostraría trivial y estéril». La traducción de textos en inglés es responsabilidad del autor.

2 «Un agente para reconstruir y reorganizar los principios morales establecidos». 
ración, toma de decisiones y acuerdos, en la perspectiva conjunta de quienes crean y muestran su trabajo y de quienes lo contemplan. Además, ser espectador de teatro tiene una dimensión social, en tanto que es un rol que se ejerce en la esfera pública. Por ello, decir teatro es decir comunidad, porque los procesos de creación implican procesos de recepción, de encuentro, en los que unos (los que crean) y otros (los que va a ver el fruto de la creación) se reconocen mutuamente.

c) Supone, pues, un pacto entre un sujeto de la creación y un sujeto de la recepción, mediante el cual el primero crea un universo en un lugar denominado escena (pudiendo ser escena cualquier espacio que decidan entre ambos), que el segundo contempla. Tiene, por lo tanto, una naturaleza simbólica, por la cual implica movimiento en los ámbitos cognitivo, emocional, cultural y social. Siempre supone tránsitos, no sólo al teatro como lugar físico sino como espacio cultural y simbólico, con sus normas de funcionamiento, y como lugar donde se recrean realidades, situaciones, conflictos y universos.

d) Es encuentro con el otro y con uno mismo, que se da en un tiempo y en un espacio determinados, y que implica un juego de relaciones en diversos niveles, sea en el de la persona que actúa, sea en el de la persona que es espectadora. Pero también es encuentro con el otro que es personaje, con sus valores, formas de vida, problemas y conflictos. Se representa al otro, a lo otro, para conocerlo, entenderlo, explicarlo e interpretarlo, porque el otro y lo otro son nuestro reflejo y nuestro espejo. Es, entonces, un medio de conocimiento que implica un posicionamiento activo ante la vida. Se recrea el mundo para aprehenderlo y como marco para entender el pasado, el presente y para proyectar el futuro, a veces desde una mirada dialéctica y crítica.

e) Es diversión, entretenimiento, recreación y contribuye al bienestar personal. En el teatro la persona puede adoptar dos roles: como sujeto que crea y como sujeto que contempla las creaciones de los demás, siendo ambos complementarios, también en el campo que nos ocupa. En efecto, Sinding, Warren y Paton (2014) plantean algunas cuestiones relevantes en relación al sintagma «social work and the arts» y señalan de partida los dos grandes hemisferios del territorio que genera esa relación: «in some initiatives people engage art as makers or doers of it, in other, as audiences or witnesses to art (that is created either by lay people or artists)» ${ }^{3}$ (p. 187). Pero en ambos casos son necesarios procesos de formación, pues todo producto cultural, en su codificación y descodificación, maneja códigos que le dan forma y sentido, pero también se vincula con una determinada forma de creación artística que hay que situar en el imaginario sociocultural del ciudadano, para que esa manifestación artística -y sus productos - sea visible, asequible, pertinente e incluso necesaria.

\section{Intersecciones: la construcción del sujeto receptor}

Nos situamos ahora ante uno de los mayores problemas que afectan al sistema teatral español, que se concreta en el concepto de «no-público» y que define y engloba un conjunto muy elevado de la población que no participa de la oferta cultural disponible en su ciudad o comarca, sea por motivos económicos sea por cuestiones no menos importantes que afectan a su capital escolar, a su capital social y a su capital teatral, y como consecuencia a su competencia estética. Para muchas personas el teatro es una manifestación cultural extraña, ajena, que no forma parte de su «habitus» (Bourdieu, 1988).

No se realizan en España estudios, de forma periódica, que vinculen el consumo cultural en artes escénicas con el nivel de estudios o el nivel de renta, pese a que en algunos se confirma que, como decía Fernández Torres (2012) en un trabajo reciente, «el público habitual o «más fiel» procede en su mayor parte de sectores con un nivel de renta superior a la media» (p. 2). En un estudio, promovido por la Red Española de Teatros y Auditorios y realizado por María José Quero (2003, p. 199), se establecía que el consumo de actividades escénicas aumenta en el mismo sentido que el nivel de estudios, y así el 85,80 por ciento de los espectadores poseían estudios medios (33,9 por ciento), universitarios medios (20,2 por ciento) y superiores ( 31,7 por ciento). El Anuario SGAE de Artes Escénicas, Musicales y Audiovisuales (Resumen Ejecutivo) de 2014 ofrecía otros datos complementarios sumamente interesantes, al señalar que:

3 «En algunas iniciativas la gente se vincula al arte como realizadores, como hacedores, del mismo, en otras, como audiencia o público del arte (que se crea por profanos o artistas)». 
Los asistentes de teatro también se han visto reducidos un 3,2\% respecto a 2012, llegando hasta los 11.160 .983 (373.477 espectadores menos). De ellos, un 32\% del total asistió a espectáculos en Madrid (3.566.512 asistentes), un 18,1\% en Cataluña (2.021.619 asistentes) y un 10,9\% en Comunidad Valenciana (1.220.268 asistentes) (p. 13).

Considerando que el espectador de teatro asiste a una media de 4 funciones por año, estaríamos ante una cifra probable de no más de 2.500.000 espectadores, de los que el 40 por ciento se ubica en Madrid y Barcelona.

Todos estos datos señalan que en España existe una tasa elevada de «absentismo» teatral, y que un numeroso grupo de personas se sitúan en lo que Quero (2013) denomina «no asistentes»o «no interesados», lo que sería un «no-público»; es decir, personas que sin tener una experiencia directa de teatro, o pensando que el teatro es una actividad ajena a su condición, se muestran totalmente refractarios a ese mundo. Evidentemente, en la perspectiva del Trabajo Social y de la política teatral cabría preguntarse si tal estado de cosas es satisfactorio, no tanto desde la posición del sistema teatral, que pierde una parte muy importante del público potencial, cuanto por el hecho de que sectores importantes de la población muestren un notable déficit de participación en la vida sociocultural de su comunidad y en el ejercicio de sus derechos.

En el prefacio al Informe Mundial sobre la Cultura (1999), Mayor Zaragoza señalaba que a la quiebra enorme entre el primer y el tercer mundo, hay que sumar unos desequilibrios importantes entre la ciudadanía del primer mundo, que tienen su origen en desigualdades económicas, sociales y educativas que potencian las culturales. Al considerar tales desequilibrios, no sólo analizamos indicadores relacionados con alimentación, vivienda o asistencia sanitaria, sino aquéllos que en el ámbito de la cultura permiten adquirir y/o afirmar conocimientos, actitudes y valores fundamentales frente a la exclusión y la marginación. En esa dirección, A.K.Sen (1999) establecía una relación directa entre cultura, libertad e independencia, apuntando que «los especialistas del desarrollo, más preocupados por alimentar a los hambrientos y por eliminar la pobreza, se irritan a menudo ante un interés por la cultura que les parece prematuro en un mundo sonde las privaciones son todavía tan numerosas» (p. 317); una relación muy necesaria en un primer mundo asediado por las tecnologías del aislamiento y de la reclusión social. Por ello Mayor Zaragoza (1995) destacaba la importancia de la cultura como forjadora de identidades y representaciones, y el rol de la creación, la difusión y la acción cultural, pues, una cultura viva es aquella «donde las personas crean, mezclan, adaptan y reinventan significados con los que puedan identificarse» (p. 5).

Es difícil imaginar el desarrollo social y económico sin un proceso similar de desarrollo cultural, por cuanto cultura y creación artística definen un determinado modelo de sociedad, patrones de conducta y de acción colectiva (Kliksberg, 1999; Martinell, 2010). Analizando la importancia de los indicadores culturales en la medida del bienestar humano, McKinley (1999) señalaba que refieren «necesidades humanas esenciales tan importantes como la necesidad de alimento, vestido y techo, aunque sean menos «físicas» o «materiales»»» (pp. 328-329).

Aquí encontramos la primera intersección entre Trabajo Social y teatro, en la necesidad de promover y demandar líneas de actuación que permitan que los «no-espectadores» adquieran el capital cultural y teatral necesarios para incrementar su competencia estética y ejercer el derecho a ser espectadores activos, capaces de incidir en la elaboración de los repertorios de teatros y compañías, de modo que entre las personas que crean y las que asumen el rol de espectadoras, se genere un diálogo fluido e inclusivo. Pero esto sólo será posible cuando se entienda que el cometido del Trabajo Social no termina en la atención primaria, en áreas básicas como la salud, la justicia o la vivienda, sino que también se debe ocupar de áreas como la cultura y las artes, en tanto que en ellas existen igualmente carencias en lo individual, lo familiar, lo grupal o lo comunitario «que tienen una vinculación íntima con la calidad de vida y el bienestar» (Fernández y Ponce de León, 2014, p. 33). Y ello nos lleva a pensar en un Trabajo Social que supere sus ámbitos básicos de intervención, pues la capacitación, el empoderamiento, la participación, la construcción de tejido social y la democratización plena sólo serán posibles a través de una intervención integral a favor de una verdadera transformación personal y social, como opina este autor.

No pocas iniciativas que se desarrollan en relación a determinados colectivos de personas que presentan un déficit de participación social 
por motivos diversos, se orientan a lograr que la democratización de la cultura sea una realidad, lo que implica poner a su alcance la posibilidad de convertirse en espectadoras habituales de teatro (Morales y Bravo, 2006; ISSP, 2013), lo que supone una afirmación personal, familiar, grupal o comunitaria en la esfera pública. En el campo de un ocio autotélico se insiste en la necesidad de que el teatro sea una de la actividades habituales en la oferta cultural, pues, asistir a un espectáculo teatral supone huir de la «domestización» (Santcovsky, 1995) y de la domesticación del ocio (Leif, 1992), e implica igualmente facilitar el encuentro de las personas en la esfera pública, visibilizando en la misma a todos los sectores de la sociedad, pero visibilizándose del mismo modo como colectivos activos que ejercen sus derechos, entre ellos, el derecho a participar en la vida cultural. Una intervención que además debe ir más allá de determinados modelos de acción instalados en la razón instrumental que pueden acabar por convertir a quien quisiéramos ver como sujetos en simples objetos. Así ocurre con determinadas campañas de oferta teatral que no buscan ofrecer un producto específico y adecuado a un sector de la población, sino incrementar el número de espectadores de un teatro o de un espectáculo.

\section{Intersecciones: la construcción del sujeto creador}

En paralelo a esa dimensión artística de la práctica teatral, hay que situar otras líneas de acción que persiguen otras finalidades, entre las que hemos de destacar aquellas que se suelen agrupar al amparo de sintagmas como: «teatro social», «teatro aplicado», «teatro de intervención», «teatro para el desarrollo personal», o incluso «teatro popular», entendido como «teatro del pueblo». Es aquí donde la práctica teatral puede mostrar su otro potencial educativo, social, cultural, político e incluso terapéutico, si bien el ámbito de las terapias teatrales es un área de la que deben ocuparse los profesionales de las ciencias de la salud con cualificación, para evitar caer en la tentación y los peligros de la «sanación»».

Cuando se habla de teatro en su dimensión social se suele situar en el horizonte un conjunto de experiencias que acaban por ocultar la riqueza enorme del campo. Así ocurre con el «teatro del oprimido» de Boal, que no es sino una más de las líneas de trabajo que se han configurado a lo largo del siglo XX, teniendo como principio fundamental la idea de un teatro para la emancipación personal, social o política (Buenaventura, 1970; Broyles-González, 1995), como ocurre en las propuestas que han compendiado Kershaw (1992), Aston (1995) o Cohen-Cruz (1998), en las que la práctica teatral se torna manifestación contra la dominación, el sometimiento o la hegemonía, en direcciones diversas, desde la perspectiva de clase, la cultural, la artística o la de género.

Thompson y Schechner (2004) proponían analizar la «bewildering nomenclature» ${ }^{4}$ que hay que considerar al invocar el sintagma «social theatre», un campo de prácticas culturales ajeno al ámbito comercial que va más allá de lo estético y que se caracteriza por tener «specific social agendas» y por su vocación de «turning «nonperformers» into performers $\rangle^{5}$ (2004, p. 12). Rasgos comunes a numerosas formas de práctica teatral que Úcar (1992) sitúa en el territorio de la «animación teatral», como antes Gourdon (1986) o Jor (1979), y todo ello vinculado con el programa de la democracia cultural (Caride y Meira, 2000).

Todo ese conjunto de prácticas teatrales que se desarrollan con fuerza en el siglo XX y que buscan (re)construir tanto el sujeto receptor como el sujeto creador en comunidades y colectivos normalmente excluidos de la esfera pública, podrían ser agrupadas en cinco grandes categorías:

a) Teatros del desarrollo personal, con procesos centrados en la promoción del potencial expresivo y creativo del individuo, con técnicas de expresión corporal y gestual, expresión oral, improvisación y dramatización (Feldenkrais, 1972; Barker, 1977; Boal, 1978, 2004; Aston, 1999), si bien en ocasiones vinculadas con otras manifestaciones artísticas como la música, la danza o la expresión plástica, con lo que nos adentramos en los territorios de la presentación y la acción escénica (Carlson, 2003).

b) Teatro popular, que todavía pervive en numerosas comunidades que mantienen determinados ritos, fiestas y celebraciones de carácter

4 «Nomenclatura desconcertante».

5 «Agenda social específica» para «convertir a los no actores en actores». 
escénico, o que se recuperan y reelaboran a través de procesos de intervención comunitaria (Schechter, 2002).

c) Teatros comunitarios, muy heterogéneos en sus prácticas, en ocasiones con carácter intergeneracional, que privilegian la expresión y la creación de la colectividad, y que en ocasiones derivan o dan continuidad a formas de teatro popular. En ocasiones aquí cabría situar prácticas de teatro aficionado o escolar en las que la dimensión artística es secundaria (Van Erven, 2001; Kuppers, 2007).

d) Teatro social, orientado fundamentalmente a la exploración de problemáticas que afectan a la colectividad y a sus individuos, pero igualmente a su (re)construcción como sujetos de acción social (Nicholson, 2005), también en una perspectiva de género (Aston, 1999), muy influidos por pensadores como Gramsci (1974) o Freire (1995), y por su pedagogía de la emancipación. Una práctica orientada a atender las «necesidades sociales» en la perspectiva de la liberación del sujeto como ser social, para contemplar «todos los aspectos que intervienen en el proceso de desarrollo integral de las personas» (Ramos Feijoo, 2006, p. 367).

e) Teatro político, que tiene sus orígenes en los teatros obreros, campesinos o de agitación y propaganda de inicios del siglo XX, y que persigue la movilización del sujeto creador y del sujeto receptor a partir de la presentación en escena de situaciones de sumisión, dominio, dependencia y explotación, y de los mecanismos para la acción individual y colectiva que permita combatirlas (Heddon y Milling, 2006; De Vicente Hernando, 2013). En ocasiones este teatro se inicia con un proceso de intervención en una determinada comunidad con la finalidad de promover su articulación y organización expresiva y creativa, al objeto de que sea ella misma la que elabore su situación y circunstancias como paso previo y necesario a la acción que de ellas se derive.

En cierto modo este conjunto de prácticas se complementan entre sí, y es habitual que teatros de desarrollo personal transiten a lo social y a lo político, en tanto su finalidad sea una transformación social asentada en la transformación personal, de grupos y colectivos. Un ejemplo paradigmático de este proceso es el que se da en Teatro Yeses, grupo de teatro de la cárcel de mujeres de Yeserías (Reiz, 2009). En otras ocasio- nes, en función de los resultados obtenidos, el tránsito se produce hacia un teatro en la que la dimensión artística toma mayor relevancia como resultado del proceso de desarrollo del grupo.

A nuestro entender, todas estas prácticas teatrales cabe integrarlas en el ámbito de la animación teatral en tanto ésta se defina como disciplina que, a medio camino entre la pedagogía social, la pedagogía teatral (Vieites, 2013) y el Trabajo Social, busca el desarrollo de personas, familias, colectivos y comunidades, mediante formas diversas de práctica teatral, poniendo el énfasis en tres ámbitos interdependientes: a) el desarrollo del potencial expresivo de la persona; b) el desarrollo de procesos creativos para dar cuerpo a narrativas individuales y colectivas; c) la promoción de espacios de encuentro para que esos procesos creativos se sitúen en la esfera pública, configurando nuevos tiempos, espacios y redes de difusión (Caride, Vieites, 2006).

Conviene con todo recordar que la animación teatral no es ajena a la dimensión que en cada caso adquiera la intervención, lo que nos lleva a la cuestión de los paradigmas vinculados a los usos del conocimiento (Habermas, 1982), si bien la adopción de una mirada asentada en la teoría crítica nos lleve directamente a propuestas de Gramsi y Freire en torno a la lucha contra la hegemonía y la emancipación, la alfabetización y a la dimensión dialógica y dialéctica de las prácticas artísticas. Y para ello, entre las personas que habitan en los territorios del Trabajo Social, de la pedagogía teatral y de la creación escénica se han de crear espacios de colaboración para generar marcos institucionales $\mathrm{y} / \mathrm{o}$ alternativos en el que desarrollar el programa antes señalado y que ahora desgranamos.

\subsection{De la expresión dramática a la expresión teatral. Recuperar cuerpo y palabra}

La construcción del sujeto creador supone, en primer lugar, la reconstrucción, recuperación y puesta en valor del sujeto como tal, y para esto último las técnicas propias de la expresión dramática son especialmente relevantes, toda vez que su finalidad última es el desarrollo del potencial creativo y expresivo de la persona, siempre en relación con capacidades, habilidades y destrezas vinculadas a la expresión oral y corporal, la improvisación y el juego de roles, la dramatización, la espontaneidad y la creatividad, y con competencias básicas como la social y la co- 
municativa, la autonomía personal y la resolución de problemas (Vieites, 2014). Esta primera fase, substantiva y fundamental para los procesos posteriores, está orientada al desarrollo de la persona como sujeto creador, con la capacidad de presentarse adecuadamente en el escenario social (Goffman, 1959), y es donde el teatro se muestra como una escuela de vida. Así, la expresión dramática, y más tarde la expresión teatral en tanto ésta se sustenta en aquélla, tienen una serie de rasgos que permiten explicar su alcance educativo por cuanto implica:

1) Creación de un marco de experiencia de carácter lúdico y ficticio (Huizinga, 1972; Goffman, 1974), a partir de la capacidad de activar el juego protagonizado (Elkonin, 1980), lo que implica un uso permanente de roles, con los que se genera la acción, que permite definir situaciones y conflictos que siempre acaban por tener o proyectar lo real, procesos de vida.

2) Creación, en consecuencia, de un tiempo y un espacio «transicionales» (Winnicott, 1971), situados en una nueva esfera que discurre en paralelo a lo real, y que se construye a partir del «como si», lo que implica crear universos de ficción a partir del razonamiento hipotético deductivo, «¿qué pasaría si?», con lo que se pueden explorar todo tipo de situaciones, de historias, de conductas, de narrativas, pero en un marco que no tiene consecuencias directas en lo real.

3) Desarrollo de competencias, capacidades y destrezas en procesos de movilización, sensibilización, desinhibición, empatía e inclusión, y de habilidades expresivas, comunicativas y creativas. Ese potencial de la persona permite la elaboración de mundos escénicos utilizando códigos y elementos de significación diversos, para trasladar esos mundos a la esfera pública, ante la mirada del otro, de los otros.

4) Recreación permanente de la alteridad, de lo otro, del otro y de los otros, también en una perspectiva de género, lo que implica una poderosa inmersión en la intersubjetividad, en la comprensión, en la empatía.

5) Elaboración permanente de una dinámica de trabajo en grupo en la que la formulación de metas comunes, la deliberación o la toma de decisiones son fundamentales para el progreso del trabajo diario; así, presencia y encuentro son as- pectos básicos de una forma de trabajo asentada en una necesaria simbiosis entre individuo y grupo, en tanto éste ofrece un marco en el que aquél se pueda desarrollar.

El desarrollo de la persona como sujeto creador no tiene otra finalidad que la recuperación y reconstrucción de un sujeto social activo, capaz de afirmar y confirmar su existencia, sus pertenencias y sus disidencias, de reclamar sus derechos asumiendo sus deberes. La alfabetización creativa y expresiva le permite iniciar el diálogo, activar la mirada y la acción dialéctica y recrear incluso su emancipación. En sus reflexiones sobre el valor educativo del teatro, Levy (2005) señala que el teatro puede ser una «call to action $\rangle^{6}$ (p. 23) pero también podría ser, como propone Freire $(1995,1997)$ la representación misma de la acción necesaria para iniciar el proceso de liberación o emancipación. Como señalaba CoburnStaege (1980), "posibilitan el abandono de pautas sociales de conducta que sean insuficientes y la creación de nuevas formas de acción» (p. 93), en tanto que permite tomar conciencia de la dominación a través de su comprensión, pero también como marco en el que ensayar la rebelión.

\subsection{La expresión teatral y la elaboración dis- cursiva propia}

Si en la fase inicial los sujetos y los colectivos que los conforman adquieren las herramientas necesarias para la (re)construcción de la experiencia y de la realidad, en esta nueva etapa, el individuo y el grupo elaboran sus propios discursos; es decir, sus narrativas escénicas, que pueden tomar en lo formal muy diversas orientaciones, desde una presentación escénica a un espectáculo convencional, en los que afirman su ser y su estar en el mundo, su visión y posición en el escenario social. El sujeto y el colectivo configuran mundos dramáticos en la escena, lo que abre la posibilidad de integrar en ese proyecto a numerosas personas que pueden aportar su saber hacer, desde un sastre que elabora indumentaria a una pintora que crea decorados. Es entonces cuando el proyecto colectivo puede tomar una dimensión plenamente comunitaria.

En el plano de los contenidos es donde ese discurso propio adquiere especial relevancia por cuanto es el momento de recrear y dar voz a las

\footnotetext{
${ }^{6}$ «Llamada a la acción».
} 


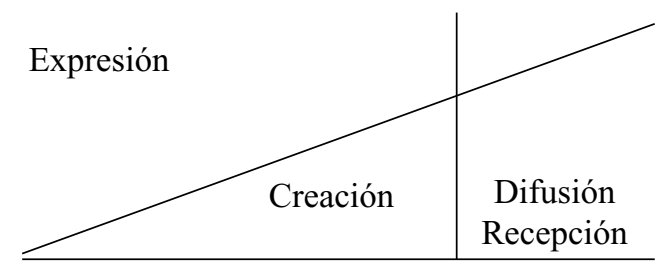

Formación

Gráfico 1. Fases de trabajo en expresión teatral. Fuente: Elaboración propia.

historias y narrativas personales, familiares, colectivas o comunitarias, en lo que acaba por ser un acto de afirmación, y de visibilización de muy diferentes problemáticas.

En el Gráfico 1 mostramos las fases de un tránsito entre la expresión dramática, que genera la alfabetización expresiva de la persona, y la expresión teatral, en la que ésta aprende a decir el mundo en una perspectiva crítica, consciente en todo momento de la mirada del otro, que es espectador, con quien delibera y debate a través del hecho mismo de compartir esa mirada convertida en acción escénica, en discurso que, finalmente, acaba por ser artístico.

\subsection{La difusión del discurso propio. Tomar y decir la palabra}

En efecto, en la última fase del proceso, el sujeto y el colectivo pasan a la esfera pública, salen a escena en lo que podemos considerar como un acto especialmente relevante en los planos social, cultural, político e incluso artístico. Es el objetivo último de la democracia cultural, cuando frente a la cultura dominante emergen otras culturas, otras voces, otras narrativas, otras formas de elaborarlas y decirlas. El sujeto teatralmente alfabetizado, libre en sus procesos de creación, asume la tarea de llevar su discurso a otras personas, colectivos y comunidades, contribuyendo de ese modo a su «alfabetización teatral», en un proceso de desarrollo y crecimiento mutuo que acaba por generar una nueva dinámica contrahegemónica en la esfera pública, combatiendo así la dependencia y la sumisión discursiva a partir de la heteroglosia (Kershaw, 1999; Goodman y De Gay, 2000; Kuppers y Robertson, 2007).

\subsection{Algunas problemáticas y riesgos}

En todo colectivo que inicia un proceso de trabajo de carácter expresivo y creativo aparecen problemáticas diversas, siendo el más evidente la necesidad de acomodar intereses y expectativas personales y formular metas comunes compartidas, que se deben revisar y adaptar de común acuerdo al desarrollo mismo del proceso. El sintagma «trabajo en proceso» es especialmente relevante aquí, pero conviene en todo momento mantener activas las finalidades últimas de la expresión dramática y teatral en un contexto de trabajo social, para evitar riesgos diversos, entre los que destacamos:

- El bucle hermenéutico. La vieja dialéctica entre proceso y producto puede acabar generando una dinámica asentada en un proceso que no tiene otra finalidad que la existencia del propio proceso. Frente a esa visión hay que destacar que proceso y producto son fundamentales, porque los últimos también son consecuencia de los primeros, pero también permiten trasladar discursos y problemáticas a la esfera pública, visibilizando emisores y mensajes.

- La ambición artística. El producto del trabajo diario y su presentación en la esfera pública se convierte en la única finalidad del colectivo, o también de la persona que ejerce labores de animación o coordinación, con lo que otras dimensiones se subordinan, lo que a veces implica que se prescinda de colaboraciones o participaciones a las que no se les supone un determinado nivel de excelencia.

- La tentación terapéutica, bastante común en grupos de trabajo que no definen con claridad la finalidad esencialmente teatral del mismo, olvidando que la propia práctica del teatro ya supone el aumento del bienestar personal.

\section{Conclusiones}

La práctica teatral se viene utilizando como herramienta de intervención en la educación y el Trabajo Social con resultados satisfactorios en campos tan diversos como la atención a personas con necesidades educativas especiales (Grady, 2000), la inclusión social (Sofer, 1997), la mediación (Tovar, 2015) o la integración (Bidegain, 2011), y una búsqueda sistemática en bases de datos ofrece un conjunto de experiencias dignas de ser consideradas. A ellas hemos de añadir algunas investigaciones de mayor calado que informan de las posibilidades de la práctica teatral como herramienta privilegiada en el Trabajo Social (Marin, 2005; Ranta-Tyrkkö, 2010) y que en buena medida señalan que las intersecciones se- 
ñaladas existen en la práctica profesional de algunas trabajadoras y trabajadores sociales que han encontrado en el teatro tanto una herramienta privilegiada para la intervención cuanto una metodología que aún estando por desarrollar cabría aplicar en la mayoría de los que tradicionalmente se consideran como métodos propios del campo (Aguilar Idáñez, 2013; Fernández y Ponce de León, 2014). Queda por realizar, con todo, un estudio sistemático de aquellas experiencias que puedan ser consideradas como buenas prácticas, en sus aspectos más relevantes, así como de las metodologías específicas que en cada caso se vienen utilizando.

Por otro lado, las intersecciones entre pedagogía teatral y Trabajo Social, implícita en todo cuanto se viene formulando, implica necesariamente una mirada interdisciplinar en la intervención que recomienda la creación de equipos que compartan saberes, formas de hacer y formas de ser en el saber y en el hacer. Resultaría sumamente costoso intentar ofrecer al profesional en Trabajo Social una formación inicial que le capacite para desarrollar proyectos y procesos de intervención asentados en las artes como instrumento, pero seguramente sea mucho menos costoso y laborioso trasladar en esa formación inicial la idea de que su intervención puede tener numerosos apoyos en la promoción de las artes como una manifestación cultural que nace de las personas y que no es patrimonio de los grandes artistas. Como decía Boal (1978): «a actividade artística é natural a todos os homens e a todas as mulheres» (p. 18), y volvemos entonces al programa de la democracia cultural con su apuesta por el pluralismo, la diversidad y el reconocimiento y la visibilidad de todos los actores sociales y culturales, y de todos los espectadores, también de los excluidos (Vidal Beneyto, 1981). Un reto común para ahora mismo.

\section{Referencias bibliográficas}

Addams, J. (1911). Twenty Years at Hull House with Autobiographical Notes. Nueva York: Macmillan. Aguilar Idáñez, M. J. (2013). Trabajo social. Concepto y metodología. Madrid: Paraninfo.

Aston, E. (1995). An Introduction to Feminism \& Theatre. Londres: Routledge.

Aston, E. (1999). Feminist Theatre Practice: a Handbook. Londres: Routledge.

Barker. C. (1977). Theatre Games. Londres: Methuen.

Bidegain, M. (2011). Teatro Comunitario argentino. Stichomythia 11-12, 81-88. Recuperado de: http://parnaseo.uv.es/Ars/Stichomythia/stichomythia11-12/pdf/estudio_8.pdf

Boal, A. (1978). Duzentos e tal exercícios e jogos para o actor e o não actor com ganas de dizer algo através do teatro. Lisboa: Cooperativa de Acção Cultural.

Boal, A. (2004). El arco iris del deseo. Del teatro experimental a la terapia. Barcelona: Alba.

Bourdieu, P. (1988). La distinción. Madrid: Taurus.

Broyles-González, Y. (1995). El Teatro Campesino. Theatre in the Chicano Movement. Austin, TX: University of Texas Press.

Buenaventura, E. (1970). Theatre \& Culture. The Drama Review, 14 (2), 151-156.

Caride, J. A. y Meira, P. (2000). La Educación social en las políticas culturales : hacia una construcción pedagógica de la democracia cultural. En J. A. Caride, Educación social y politicas culturales (pp. 19-42). Santiago de Compostela: Tórculo.

Caride, J. A. y Vieites, M. F. (eds.) (2006). De la educación social a la animación teatral. Gijón: Trea. Carlson, M. (2003). Performance. A Critical Introduction (2nd. Edition). Nueva York: Routledge.

Cohen-Cruz, J. (ed.) (1998). Radical Street Performance. Londres: Routledge.

Coburn-Staege, U. (1980). Juego y aprendizaje. Madrid: Ediciones de la Torre.

De Vicente Hernando. C. (2013). La escena constituyente. Madrid: Centro de Documentación Crítica.

Dieste, R. (1995). La vieja piel del mundo. En R. Dieste, El alma y el espejo (pp. 201-280). Madrid: Alianza.

Elkonin, D. B. (1980). Psicología del juego. Madrid: Visor.

Feldenkrais, M. (1972). Awareness through Movement. Nueva York: Harper \& Row.

Fernández García, T. y Ponce de León Romero, L. (2014). Nociones básicas de trabajo social. Madrid: UNED.

Fernández Torres, A. (2012). El público de teatro en la España del siglo XXI. Don Galán, 2. Recuperado de: http://teatro.es/contenidos/donGalan/donGalanNum2/sumario.php 
Freire, P. (1995). Pedagogía del oprimido. (46 ed.). México: Siglo XXI.

Freire, P. (1997). La Educación como práctica de la libertad. (45 ed.). México: Siglo XXI.

Goffman, E. (1959). The Presentation of Self in Everday Life. Nueva York: Anchor Books.

Goffman, E. (1974). Frame analysis: An essay on the organization of experience. Londres: Harper and Row.

Goodman, L. y De Gay, J. (eds.) (2000). The Routledege Reader in Politics and Performance. Londres: Routledge.

Gourdon, A-M. (ed.) (1986). Animation, Théâtre, Societé. Paris: Éditions du CNRS.

Grady, S. (2000). Drama and Diversity. A pluralistic perspective for educational drama. Portsmouth, NH: Heinemann.

Gramsci, A. (1974). Antología. Madrid: Siglo XXI.

Habermas, J. (1982). Conocimiento e interés. Madrid: Taurus.

Heddon, D. y Milling, J. (2006). Devising Performance. Londres: Palgrave.

Huizinga, J. (1972). Homo ludens. Madrid: Alianza.

ISSP. (2013). Velhices: experiências e desafios nas políticas do envelhecimento ativo. Temas em Saúde Coletiva, 14. Recuperado de: http://www.saude.sp.gov.br/resources/instituto-de-saude/homepage/temas-saude-coletiva/pdfs/velhices_envelhecimento_ativo_pdf.

Jor, F. (1979). La desmitificación de la cultura. Madrid: Ministerio de Cultura.

Kershaw, B. (1992). The Politics of Performance. Radical Theatre as Cultural Intervention. Londres: Routledge.

Kershaw, B. (1999). The Radical in Performance. Londres: Routledge.

Kliksberg, B. (1999). El rol del capital social y de la cultura el en proceso de desarrollo. Revista Venezolana de Gerencia, 9, 11-50.

Kuppers, P. (2007). Community Performance. An Introduction. Nueva York: Routledege.

Kuppers, P. y Robertson, G. (eds.) (2007). The Community Performance Reader. Londres: Routledge.

Leif, J. (1992). Tiempo libre y tiempo para uno mismo. Madrid: Narcea.

Levy, J. (2005). Reflections on How Theatre Educates. The Journal of Aesthetic Education, 39 (4), 20-30.

MacKaye, P. (2015). Por un teatro cívico. Madrid: Publicaciones de la ADE.

Marib, Ch. (2005). Breaking Down Barriers, Building Dreams: Using Theatre for Social Change to Explore the Concept of Identity with Latina Adolescents. Phoenix, AZ: Arizona State University.

Martinell, A. (coord.) (2010). Cultura y desarrollo. Un compromiso para la libertad y el bienestar. Madrid: Siglo XXI y Fundación Carolina.

Mayor Zaragoza, F. (1999). Prefacio. En VV. AA., Informe mundial sobre la cultura (pp. 5-6). Madrid: UNESCO, Acento y Fundación Santa María.

McKinley, T. (1999). Medida de la contribución de la cultura al bienestar humano: los indicadores culturales del desarrollo. En AA. VV., Informe mundial sobre la cultura (pp. 322-332). Madrid: UNESCO, Acento y Fundación Santa María.

Morales, M. y Bravo, I. (2006). El ocio terapéutico. En J. Giró Miranda (coord.), Envejecimiento activo, envejecimiento en positivo (pp. 133-154). Logroño: Universidad de La Rioja.

Nicholson, H. (2005). Applied drama. The gift of theatre. Nueva York: Palgrave Macmillan.

Onieva, J. L. (2011). La dramatización como recurso educativo estudio de una experiencia entre estudiantes malagueños de un centro escolar concertado y adolescentes puertorriqueños en situación de marginalidad. Tesis doctoral leída en la Universidad de Málaga. C. González Álvarez (dir.). Recuperado de: http://riuma.uma.es/xmlui/handle/10630/4892

Quero, M. J. (2003). Marqueting cultural. El enfoque relacional en las entidades escénicas. Madrid: La RED.

Quero, M. J. (2013). Los públicos de la cultura. Cádiz: Universidad de Cádiz.

Ramos Feijóo, C. (2006). Las necesidades sociales. En T. Fernández García y C. Alemán Bracho (coords.), Introducción al trabajo social (pp. 340-372). Madrid: Alianza Editorial.

Reiz, M. (2009). Elena Cánovas y el teatro Yeses. Un Proyecto artístico y social. Primer Acto, 331, 49-54. 
Santcovsky, H. (1995). Los actores de la cultura. Barcelona: Hacer.

Schechter, J. (ed.) (2003). Popular Theatre. A Sourcebook. Londres: Routledge.

Sen, A.K. (1999). Cultura, libertad e independencia. En AA. VV., Informe mundial sobre la cultura (pp. 317-321). Madrid: UNESCO, Acento y Fundación Santa María.

SGAE. (2014). Anuario SGAE de las artes escénicas, musicales y audiovisuales. Recuperado de: http://www.anuariossgae.com/anuario2014/home.html

Sinding, Ch., Warren, R. y Paton, C. (2014). Social work and the arts: Images at the intersection. Qualitative Social Work, 13 (2), 187-202.

Sofer, R. (1997). «Mujeres en la encrucijada»: teatro comunitario social como un proceso potenciador orientado a la inclusión social. Servicios Sociales y Política Social, 38, 103-107.

Ranta-Tyrkkö, S. (2010). At the Intersection of Theatre and Social Work in Orissa, India: Natya Chetana and Its Theatre. Tesis doctoral presentada en Tampere University. Recuperado de: https://tampub.uta.fi/handle/10024/66605

Tovar, P. (2015). Una reflexión sobre la violencia y la construcción de paz desde el teatro y el arte. Universitas humanística, 80, 347-372.

Úcar, X. (1992). El teatro en la animación sociocultural. Zaragoza: Diagrama.

Van Erven, E. (ed.) (2001). Community Theatre. Global Perspectives. London: Routledge.

Vázquez Aguado, O. (2006). Teorías de las principales figuras del Trabajo Social. En T. Fernández García y C. Alemán Bracho (coords.), Introducción al trabajo social (pp. 110-130). Madrid: Alianza Editorial.

Vidal Beneyto, J. (1981). Hacia una fundamentación teórica de la política cultural. Revista Española de Investigaciones Sociológicas, 16, 123-134.

Vieites, M. F. (2013). La construcción de la pedagogía teatral como disciplina científica. Revista española de pedagogía, 71, 493-508.

Vieites, M. F. (2014). Educación teatral: una propuesta de sistematización. Teoría de la Educación, 26(1), 77-101.

Spolin, V. (1963). Improvisation for the Theatre. Evaston, IL: Northwestern University Press.

Thompson, J. y Schechner, R. (2004). Why Social Theatre? The Drama Review, 48(3), 11-17.

Winnicott, D. W. (1971). Playing and Reality. Londresn: Tavistock. 